\title{
Paisajes culturales y alteridad caribeña en el diario de "Viage a la America" de fray Íñigo Abbad y Lasierra
}

\section{Fidel Rodríguez Velásquez ${ }^{1}$}

\section{Resumen Recepción: 18 de julio de 2018 / Aceptación: 25 de setiembre de 2018}

El presente trabajo estudió la construcción de paisajes culturales y alteridades caribeñas en el diario de "Viage a America" de fray Íñigo Abbad y Lasierra (17721774). Para ello se realizó un análisis textual de su crónica cotidiana de sucesos en la travesía por las islas de Puerto Rico, Margarita y Trinidad, con el objeto de dar cuenta de la forma como él vivió las geografías, personas, animales y costumbres de estas regiones. El relato de este fraile benedictino puede entenderse a partir de dos dimensiones, una antropológica que expone el universo cultural del propio viajero en el cual se encontraron elementos de la ilustración europea con elementos de la Europa medieval, y una dimensión sociohistórica que señala los esfuerzos de este viajero por ver la región como un espacio atrasado pero con una potencialidad importante que ha sido poco aprovechada por quienes habitan estas regiones y por quienes fueron enviados por la corona española para hacerlo. De estas dos dimensiones emergen los paisajes culturales que fray Íñigo Abbad y Lasierra representa textualmente en su diario de viaje.

\section{Palabras clave}

Caribe; siglo XVIII; fray Îñigo Abbad y Lasierra; paisajes culturales; diario de Viajes

\section{Abstract}

The present work studied the construction of cultural landscapes and Caribbean alterities in the diary of "Travel to America" by fray Ínigo Abbad y Lasierra (1772-1774). To this end, a textual analysis was made of his daily chronicle of events in the crossing of the islands of Puerto Rico, Margarita and Trinidad, in order to account for the way he lived the geographies, people, animals and customs of these regions. The story of this Benedictine Friar can be understood from two dimensions, an anthropological one that accounts for the cultural universe of the traveler in which elements of European enlightenment were found with elements of medieval Europe, and a sociohistorical dimension that accounts for the efforts of this traveler to see the region as a backward space but with an important potential that has been little used by those who inhabit these regions and by those who were sent by the Spanish crown to do so. From these

1 Venezolano. Antropólogo egresado de la Universidad Central de Venezuela (UCV). Candidato a Magister en Historia de las Américas por la Universidad Católica Andrés Bello (UCAB). En la Actualidad se desempeña como Profesional Asociado a la Investigación en el Laboratorio de Etnohistoria y Oralidad del Centro de Antropología "J.M. Cruxent" del Instituto Venezolano de Investigaciones Científicas (IVIC). Correo electrónico: fidelrodv@gmail.com 
two dimensions emerge the cultural landscapes that fray Íñigo Abbad y Lasierra textually represent in his travel diary.

\section{Keywords}

Caribbean; eighteenth century; fray Îñigo Abbad y Lasierra; cultural landscape; travel journal

\section{Resumo}

Este trabalho estudou a construção de paisagens culturais e alteridades caribenhas no diário de "Viage a America" do frei Iñigo Abbab y Lasierra (1772 -1774). Para isto, realizou-se a análise textual de sua crónica cotidiana dos eventos da travessia das ilhas de Porto Rico, Margarita e Trinidade, a fim de explicar como ele viveu as geografias, pessoas, animais e costumes dessas regiões. A história deste frei beneditino pode ser compreendida a partir de duas dimensões. A primeira delas antropológica que representa o universo cultural do próprio viajante, na qual se encontram elementos do iluminismo europeu e da Europa medieval. A outra dimensão, a sócio histórico põe em evidencia os esforços desse viajante em ver a região como um espaço atrasado, mas com um potencial importante que foi pouco explorado tanto por aqueles que a habitavam como pelos enviados pela coroa espanhola. Dessas duas dimensões emergem as paisagens culturais que frei Iñigo Abbab y Lasierra representa textualmente em seu diário de viagem.

\section{Palavras chave}

Caribe; século XVIII; frei Íñigo Abbad y Lasierra; paisagens culturais; diário de viagem

\section{Introducción ${ }^{2}$}

Los paisajes culturales son una expresión del habitar, es decir que se crean a partir de las prácticas sociales y las relaciones que establecen los seres humanos con su entorno; interpretarlo y describirlo es un proceso diferente puesto que solo se puede aprehender un paisaje a partir de la vivencia personal del mismo, es decir, a partir de la puesta en marcha del aparto sensitivo humano, el cual a su vez estará mediado por la cultura. De esta forma, el paisaje puede definirse como "la suma de un todo ecológico, histórico y geográfico y otro todo interpretativo” (Martínez, 2017, p. 43). Esta afirmación tuvo implicaciones en términos de la forma como nos aproximamos al estudio de los paisajes caribeños en el pasado, puesto que permitió situar las fuentes que utilizamos no solo en un marco cronológico, sino también en un marco cultural (Rodríguez Velásquez, 2017). Esta distinción a la que

$2 \quad$ Todas las citas del diario de "Viage a la America" de fray Íñigo Abbad y Lasierra fueron transcritas literalmente de la edición facsimilar del manuscrito original de este viajero publicada por Armitano Editores en Caracas, Venezuela en el año de 1974. Es necesario hacer notar que la grafía y las reglas gramaticales del castellano de la época son diferentes a las actuales. Sin embargo, se decidió respetar la forma original escrita por el autor del diario. Cabe destacar que esta edición carece de numeración, por lo cual las citas textuales no aportan esa información. 
hacemos referencia, toma especial importancia cuando el estudio histórico involucra sujetos con diferentes marcos culturales de referencia, los viajeros son ejemplos de esta condición puesto que, generalmente, sus diarios se transforman en miradas etic ${ }^{3}$ acerca de los lugares y personas que estos se proponen describir y/o analizar.

Con el inicio de la presencia europea y africana en los territorios americanos, se inició en simultáneo la tarea de documentar todo lo que fuese posible acerca de la realidad americana, muchas veces por órdenes directas de la corona y, otras, por intereses particulares de orden eclesiástico y/o comercial. Estas narraciones y descripciones tenían importantes variaciones marcadas por el universo cultural al que pertenecía su autor, por lo que una misma región visitada por diferentes viajeros podía ser interpretada y descrita de múltiples y diferentes maneras. Así, se encuentran desde las visiones más realistas de fenómenos y hechos, hasta las versiones más fantasiosas que hablaban de temibles monstruos, animales marinos gigantes y protohumanos que tenían sus cabezas en el pecho. Para el caso venezolano y su fachada caribeña, muchos de estos viajeros han sido ampliamente estudiados en trabajos como los de Angelina Lemmo (1983); Nelly Arvelo-Jiménez y Horacio Biord-Castillo (1989); Vladimir Acosta (1992; 1993); Elías Pino Iturrieta y Pedro Calzadilla (1993); Miguel Ángel Perera (1993); Emanuele Amodio (1993); Rodrigo Navarrete (2004) y Giovanna Montenegro (2017).

Sin embargo, no todos los espacios territoriales, ni todos los viajeros han gozado de la misma atención, nuestro caso de estudio: fray Íñigo Abbad y Lasierra es justamente uno de los viajeros que ha sido poco estudiado de manera específica, pese a ofrecer una crónica sumamente clave por su transitar por las islas de Puerto Rico, Trinidad y Margarita en la segunda mitad del siglo XVIII (Mapa 1). Sobre él, destacan los trabajos de Antonio Baso Andreu (1993) titulado "Andadura americana de fray Íñigo Agustín Abbad y Lasierra y algunos pasos más" y el de Sergio Martínez Sarrado (2001) "Evangelización y cultura: un enriquecimiento mutuo según Agustín Íñigo Abbad y Lasierra" ambos interesados en la figura de este hermano benedictino como una expresión de los aportes de los aragoneses a la empresa hispana en los territorios americanos.

3 Marvin Harris (1998) define lo etic en contraposición de emic, es decir, en un contexto dado la visión etic corresponderá a la visión desde fuera de la cultura que se observa y lo emic corresponderá a la visión propia de la cultura.

4 Aunque el diario de "Viage a la America" también da cuenta de la visita de fray Íñigo Abbad y Lasierra también trata sobre la visita a las provincias de Barcelona, Nueva Barcelona, Cumaná y el Orinoco, nuestro análisis solo se refiere a su paso por las islas de Puerto Rico, Margarita y Trinidad. 
Mapa 1. Islas visitadas por fray Íñigo Abbad y Lasierra

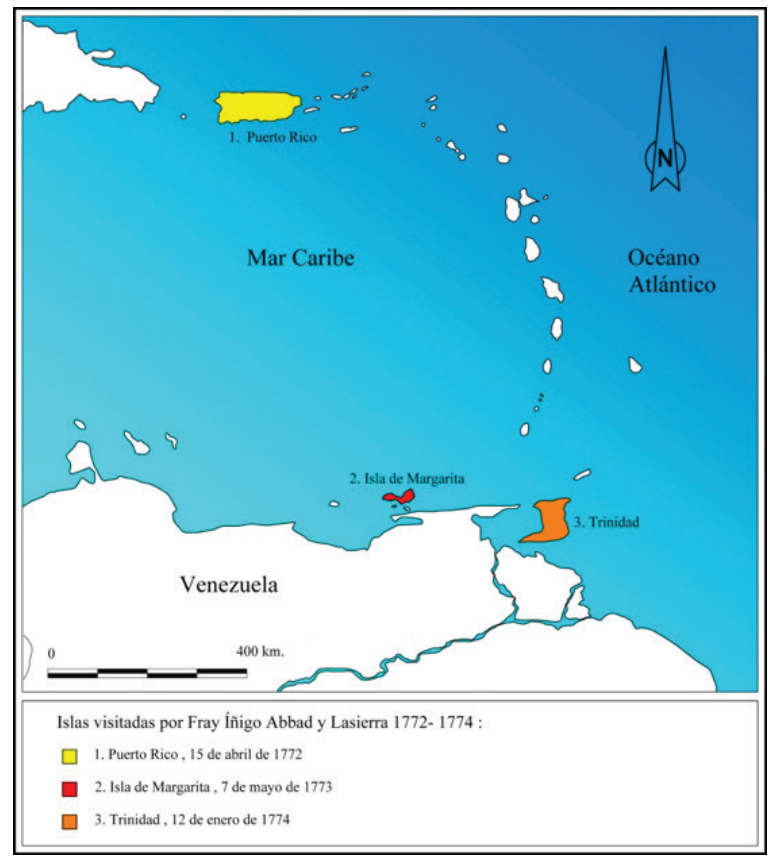

Fuente: Elaboración propia.

Ante esta realidad hemos decidido dedicar el presente trabajo al estudio de los paisajes culturales y la alteridad caribeña en el diario de "Viage a la America" de fray Ínigo Abbad y Lasierra (1772-1774). Viajero nacido en la localidad de Estadilla ubicada en Aragón, península ibérica. Se desempeñaba como un hombre de iglesia que pasaba muchas horas dedicado al cultivo del intelecto. El nombramiento de su hermano benedictino fray Manuel Jiménez Pérez como obispo de Puerto Rico en el año de 1771, fue la oportunidad perfecta para poner en práctica sus conocimientos. De esta manera, como él mismo señala, "En quince de abril de mil setecientos setenta y dos, nos levamos de la Bahía de Cádiz, para la ysla de Puerto Rico, con viento leste Hojo, que nos calmó aquella noche". Una vez en Puerto Rico dedicó su primer bienio a acompañar al obispo en su visita pastoral por toda la diócesis que, para entonces, estaba conformada además por las provincias de Cumaná, Margarita, Nueva Barcelona, la cuenca del río Orinoco y la isla de Trinidad.

Las notas de viaje que tomó durante este periplo eclesiástico fueron la base sobre las que fray înigo Abbad y Lasierra construyó, posteriormente del otro lado de la cuenca atlántica, este diario de "Viage a la America", cuyo resultado es más bien una mezcla entre sus observaciones y sus lecturas de otros viajeros que antes que él transitaron por los caminos de los territorios americanos, esto queda asentado en el diario cuando señala que "Los que más de propósito han escrito sobre la provincia de la Nueva Andalucía y Guayana son los padres Gumilla, y Caulin, yo llevaba con migo el primero, é hiba 
observando sus descripciones naturales y geográficas". Esta práctica no fue exclusiva de Abbad y Lasierra, por el contrario, fue una de las características distintivas de los viajeros de la segunda mitad del siglo XVIII.

Aclarados estos elementos de orden teórico y práctico, se organizó esta lectura histórico-antropológica de los paisajes culturales del diario de fray Íñigo Abbad y Lasierra en tres secciones; en la primera se llevó a cabo una ponderación temporal y cultural de la fuente, así como precisiones en torno al Caribe de la época; la segunda de ellas se ocupó de las relaciones geográficas y la representación que de esta nos ofrece en el diario; y la última sección se dedicó a discutir las construcciones sociales que hace Abbad y Lasierra acerca de quienes, para el momento de su visita, habitaban los territorios caribeños.

\section{La segunda mitad del siglo XVIII: una ponderación política, temporal y cultural de la fuente}

El siglo XVIII será conocido también -a posteriori- como el siglo de la Ilustración, o como señala Bracho (2009, p. 56), "el tiempo de la filosofía, ... de la filosofía de la historia, así como el tiempo de la razón y la idea de progreso", haciendo referencia a la construcción "racional" y "hegemónica" del mundo que tendrá lugar en esta época desde Europa. Comprender esta visión del mundo impulsada por pensadores como Buffon, De Pauw, Montesquieu, Hume, Voltaire, Diderot y Kant, será fundamental para comprender la mirada de los viajeros del siglo XVIII, pues estos proyectaron sobre los territorios americanos las ideas ilustradas, construyendo o reafirmando los prejuicios ideológicos que la Europa dieciochesca tendrá sobre América.

Este siglo será además, clave en la consolidación del modelo colonial sobre los territorios ultramarinos, con el afianzamiento de las instituciones coloniales y de una legislación que buscó normar en términos impositivos a una sociedad étnicamente diversa, donde coexistieron, al mismo tiempo, múltiples instituciones sociales que responden a diferentes lógicas culturales y donde "el poder de occidente se visualiza en su capacidad para ejercer influencia en la conformación de las subjetividades desde el siglo XVI" (Bracho, 2009, p. 78). Será justamente en esta tarea de construcción y reconstrucción de subjetividades donde los viajeros tendrán un papel preponderante. Su tarea nunca se dio por terminada, incluso más de 150 años después del inicio de la presencia europea y africana en los territorios americanos. Es decir, que tanto cronistas como viajeros, siguieron llevando adelante su labor hasta incluso el final de la Colonia y el inicio de las repúblicas independientes en América, debido a que estas expediciones contribuirán a transformar significativamente las miradas científicas de la época, pues tendrán un papel preponderante en la resolución de problemas astronómicos, geológicos, cartográficos, biológicos, físicos, entre otros. 
Por ello, es posible clasificar a estos "etnógrafos" del proceso de conquista y colonización de los territorios americanos, siguiendo dos criterios: el cronológico y el rol social jugado. Según el primer criterio, los viajeros se dividen en: 1) Tempranos: lo cual abarcaría a aquellos que visitaron América entre finales del siglo XV y la primera mitad del XVI; 2) Medios: que visitaron América entre la segunda mitad siglo XVI y el siglo XVII; 3) Tardíos: quienes realizaron sus crónicas fundamentalmente durante el siglo XVIII. Según el rol social de los viajeros también pueden dividirse en cronistas, clérigos, soldados y comerciantes, aunque se hallaran algunos donde estas funciones se ven solapadas $u$ otros donde cambiaron entre una u otra en el tiempo.

Siguiendo esta clasificación, puede ubicarse a fray Íñigo Abbad y Lasierra como un viajero tardío que desempeñó su papel de clérigo, pero con una visión claramente utilitaria y/o comercial cuando analizamos aquellos temas a los cuales le dio importancia en sus relatos del Caribe de la segunda mitad del siglo XVIII. Los viajeros de este periodo serán denominados también por Calzadilla (2005) como viajeros ilustrados, con la idea de marcar una clara diferencia entre aquellos cuya visión estaba más orientada a la mirada científica de la época y aquellos donde la visión escolástica dominaba en los relatos donde narraban su transitar por el Atlántico entre los siglos XVI, XVII, e incluso, a principios del siglo XVIII. Emanuele Amodio (2002, p. 212) ilustra bien esta proposición cuando señala a propósito del Orinoco Ilustrado y defendido de Gumilla (1745) y El Ensayo de Historia Americana de Felipe Salvador Gilij [1782] (1955) que:

Entre ambos libros media un abismo. En el primer caso, nos encontramos frente a una visión barroca, donde el indio es presa del demonio y la obra sirve para identificar sus huellas y guiar a los futuros misioneros; en el segundo, la obra se despliega como una investigación que pretende responder positivamente a las imágenes distorsionadas del mundo americano y de sus primigenios habitantes que se producían en Europa.

Otro elemento sumamente importante por considerar a la hora de ponderar el diario de viaje, tiene que ver con las concepciones del espacio y la cartografía que se tenían para la época. El espacio geográfico que hoy denominamos "Caribe" fue durante los siglos XVI, XVII y primera mitad del siglo XVIII, un espacio de confrontación permanente en el ámbito militar, político y económico, pero al mismo tiempo, un espacio donde el pensamiento medieval y el pensamiento moderno se disputarán influencia. El análisis de las cartografías de la época ofrece un buen resumen al respecto; por ejemplo, el mapa de Girolamo Verrazzano (1529) dividió al Caribe en dos sectores claramente diferenciados, por un lado, las Antilie Insulae correspondientes a las Ilamadas Antillas Mayores y, por otro, Insulae de Canibali para las Antillas menores (von Grafenstein, 2000). Como salta a la vista, la idea de los indígenas caníbales había impregnado tempranamente al universo cultural europeo 31 y siguió teniendo una marcada influencia hasta la segunda mitad del siglo 
XVIII. Para el siglo XVII, seguirá sin aparecer el nombre de mar Caribe, por el contrario, la cartografía europea seguirá representando a este simplemente como parte del Atlántico o del Mar del Norte como era más frecuentemente denominado (Mapa 2).

Mapa 2. Vicente de Memije, Aspecto geográfico del mundo Hispánico

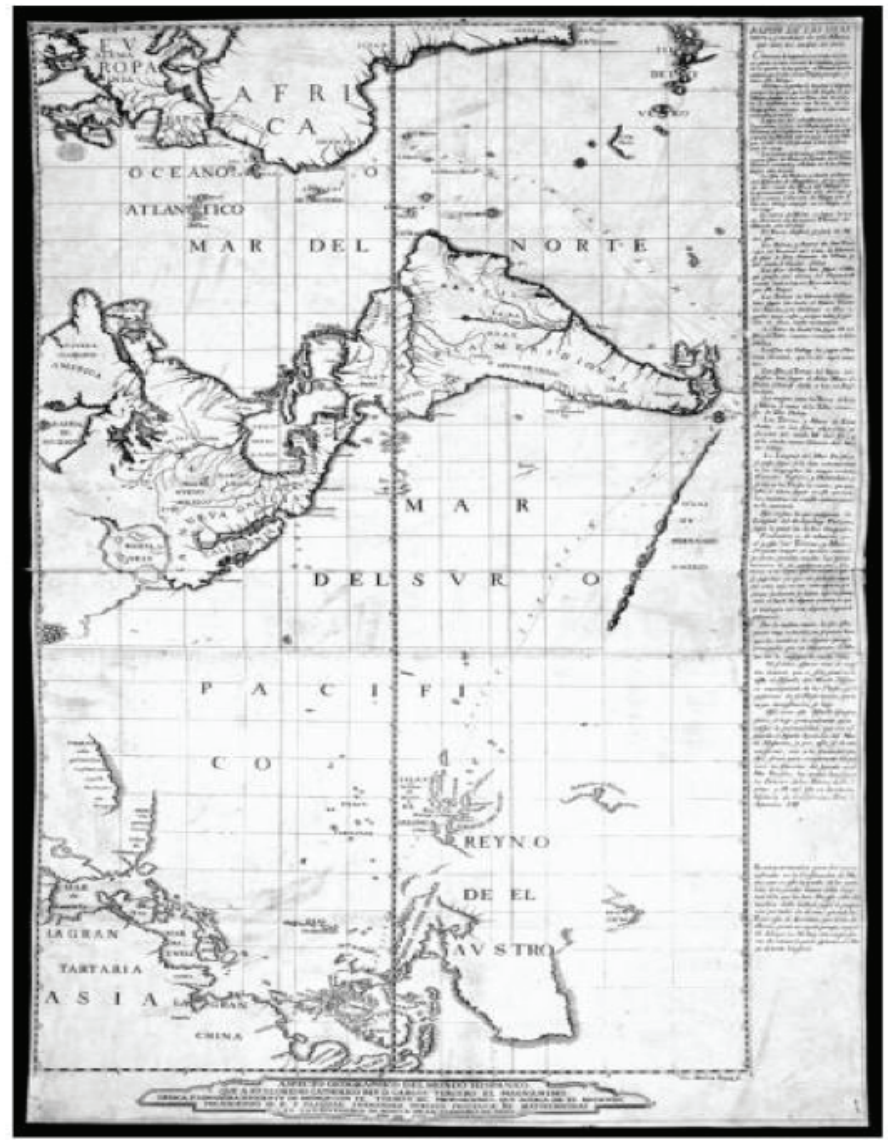

Fuente: Brückner, 2011, p. 23.

Como señala von Grafenstein (2000), serán los ingleses los primeros en utilizar la denominación mar Caribe para referirse a este espacio territorial a mediados del siglo XVIII en una edición inglesa de un mapa francés publicado en el año de 1746, que luego fue ampliamente reeditado y difundido en los años de 1758, 1767, 1775 y 1794. Otras denominaciones que también fueron comunes en la época son las de islas de Barlovento y de Sotavento. La primera referida a las pequeñas Antillas, mientras la segunda referida a Margarita, Aruba, Curazao y el resto de las islas que forman parte de la actual Venezuela.

También es importante considerar, además de la cartografía, que la segunda mitad del siglo XVIII estuvo marcada por una reconfiguración del escenario político europeo (Morelli, 2008). Las llamadas guerras napoleónicas 
generaron conflictos importantes entre Inglaterra y Francia y tuvieron serias consecuencias en el escenario global de la época, sobre todo en cuanto al control de las grandes rutas de navegación y comercio marítimo en el Atlántico y más específicamente en el Caribe. Esta reconfiguración abrió paso a que las alianzas comerciales de libre circulación de mercancías empezaran a tomarse como elementos centrales de las relaciones de los imperios, lo cual obligó a España a desmontar paulatinamente las restricciones al comercio que databan desde los primeros momentos de la Conquista y Colonización de los territorios americanos.

De esta manera, para la fecha en que Abbad y Lasierra visitó el Caribe, puede afirmarse que se encontró con un espacio territorial caracterizado no solo por el contacto interétnico con los diversos pueblos indígenas americanos, sino por una intensa competencia en el plano económico de los imperios europeos -entiéndase españoles, ingleses, franceses y holandesesque tenían en el Caribe de la fecha, una de sus más preciadas regiones de producción económica y una fuente casi inagotable de productos como el cacao, la sal y el azúcar.

\section{Paisajes culturales en el diario de fray Íñigo Abbad y Lasierra}

La construcción del paisaje será siempre una visión personal, como señala Cunill Grau "no existe un paisaje inmutable, que objetivamente proporciona su biodiversidad y sus recursos naturales. Todo paisaje es interpretado y percibido variablemente por las geografías personales" (2004, pp. 2526). Desde esta visión, el paisaje fue entendido como el resultado de una mirada específica, es decir, como un producto cultural que tendrá lugar en un tiempo histórico determinado, en este caso, la segunda mitad del siglo XVIII. Asimismo, fue representando, ordenado y estructurado de acuerdo con los esquemas culturales de nuestro viajero, por lo que sirvió además para analizar el despliegue del universo cultural al que pertenecía fray Íñigo Abbad y Lasierra. Así, sus anotaciones y precisiones mostraron sus formas de ver y comprender el mundo, al mismo tiempo que permitieron profundizar en el pasado del Caribe por él visitado.

El diario nunca ofrece una visión de conjunto de los territorios caribeños, pues se estructura isla por isla, empieza por Puerto Rico, luego Margarita y, por último, Trinidad. Sin embargo, la representación de los paisajes culturales siempre tuvo puntos de articulación y divergencia. La primera segmentación por él ofrecida fue la denominación dada a este conjunto de islas cuando señala "Estas yslas son conocidas desde su descubrimiento con el nombre de Antillas, pero por los vientos que les soplan quasi siempre, llaman de barlovento alas más orientales, y de sotavento alas situadas más al occidente". Bajo esta 33 distinción, Margarita fue la única isla de Sotavento por él visitada mientras 
que Trinidad, la isla de Barlovento y Puerto Rico pertenecerán a las grandes Antillas. De esta manera, el viento fue el primer elemento que sirvió de marcado diferenciador de los países de las islas visitadas, pues fue el insumo principal para demarcar espacios fronterizos en un caribe que de alguna manera se pensaba como un espacio homogéneo.

Los paisajes culturales de convergencia entre las tres islas serán aquellos propios de los territorios insulares de la región visitada. Apenas empieza a vislumbrar las costas, nuestro viajero señalará que "Estas yslas parecen altas montañas que se han separado de la tierra firme, sumergiéndose la tierra baja por alguna violenta revolución de los mares o terremotos", dando cuenta de la ideas geológicas y geográficas que se tenían para la época sobre la formación de la islas; asimismo, continúa su relato señalando que "por todas partes, los conchales de todas especies de caracoles, los corales, los bancos de ostras, los pescados de mar que se encuentran en diferentes lugares de la tierra", de esta manera se encuentra con los principales recursos naturales de la zona y que constituirían el eje central sobre el que se edificarán los paisajes caribeños.

Una vez desembarcado en la isla de Puerto Rico el 25 de abril de 1772, dará inicio a su construcción narrativa de los países culturales caribeños de las islas de Puerto Rico, Margarita y Trinidad (Tabla 1). Como hombre del clero dará mucha importancia en sus recorridos a la arquitectura de las iglesias. Sobre la construida en esta primera isla dirá "se erigió en ocho de agosto de mil quinientos once por la santidad de Julio Segundo", sobre su estructura comentará "es de tres naves de muy buena arquitectura sus paredes cornisas y columna son de piedra de sillería, pero solo la capilla maior está cubierta de bóveda". Relatos similares estarán siempre presentes en los inicios de sus relatos tanto en Margarita como en la isla de Trinidad, en esta última señalará "su iglesia aunque de bahareque está bastante aseada". La distinción en términos de los materiales constructivos será una constante en la narrativa de fray Íñigo Abbad y Lasierra con lo que siempre marcará una distancia con las construcciones de bahareque por considerarlas de menor calidad.

Tabla 1. Relación de los paisajes culturales visitados por fray Íñigo Abbad y Lasierra

\begin{tabular}{|l|l|l|}
\hline Lugar & Pueblos visitados & Ganado \\
\hline Isla de Puerto Rico & 30 & Sin datos \\
\hline Isla de Margarita & 6 & 39312 \\
\hline Isla de Trinidad & 9 & 5649 \\
\hline
\end{tabular}

Fuente: Elaboración propia. 
Otro elemento convergente en los paisajes culturales será la dificultad con la que nuestro viajero se enfrentará al mar en su navegación por estas islas, de ello da cuenta la siguiente cita:

La inestabilidad del océano que perpetuamente la bate, roba y trastorna prueban estas vicisitudes y que este archipiélago como el de las Indias Orientales, situado casi a la misma altura se ha formado por una misma causa: el movimiento del mar de oriente a poniente.

De esta manera, lo anterior expone las dificultades que representaban para la fecha la navegación circuncaribeña y cómo el mar, de alguna manera, era central para comprender como un todo esta región del Atlántico.

Las distinciones en términos de los paisajes culturales iniciarán con el clima de las islas. Sobre Puerto Rico dirá "comúnmente solo se distinguen en esta ysla dos estaciones la de lluvias y la de la seca"; asimismo, muestra clara perturbación por las continuas tormentas que azotaron las islas durante su visita al punto que señalará "el uracan es el phenomeno más orroroso de quantos se observan en esta ysla y aunque creo que en toda la América: es un viento furioso, acompañado de lluvia, relámpagos y truenos, y algunas veces de temblores de tierra". Estos serán además, acompañados de "los temblores de tierra [que] se hacen sentir muchas veces, y algunas con violencia y por lo común en el curso o el fin de la estación de las lluvias".

Sobre Trinidad y Margarita no hará referencia a este tipo de fenómenos puesto que, a su parecer, en estas islas, solo se encuentra una estación seca y ninguna de lluvia. En palabras del viajero "Todo el terreno de esta ysla es estéril y escabroso, cortado de cerros, que dejan algunos valles de arena, tan áridos y secos que solo están cubiertos de tunas que llaman ygueras de indias". Esta visión será completada cuando señala que:

Esta tan escasa de agua que solo hay en toda la ysla dos arroyuelos de tan poco caudal que el más abundante no corre una legua, a lo que se agrega la falta de lluvia, cuando siempre su cielo tan despejado y sereno que suelen pasarse años sin disfrutar el beneficio de la lluvia.

En este sentido, lejos estará nuestro viajero de los primeros cronistas que consideraron que cerca de estos territorios se encontraría el paraíso terrenal, pues para él la sequía constante y la falta de agua eran una de las dificultades principales a sortear para el pleno aprovechamiento de los potenciales de estas islas. Otro elemento por considerar a la hora de analizar los paisajes culturales, serán las ideas acerca de los animales marinos. Aunque hemos señalado anteriormente que los viajeros de la segunda mitad del siglo XVIII, en líneas generales, se distanciaban de sus pares anteriores por haber superado el pensamiento mítico monstruoso, en los relatos de fray Íñigo Abbad y Lasierra vuelven a aparecer los monstruos marinos que acompañaron el imaginario de los primeros cronistas que visitaron los territorios americanos, el mismo Colón 
influenciado por la lectura del Milione de Marco Polo describirá en sus diarios sus encuentros personales con estos monstruos americanos.

El viajero en su paso por la isla de Margarita relató que "entre los monstros marinos más carnívoros y comunes en estas costas son los tiburones y las mantas", esta última será incluso la más temida, pues la describe como una

especie de cerdos de mar muy grandes y de una tez parda obscura, su boca rasgada y poblada de dos andanadas de grandes colmillos por cada lado que afianzan a un hombre por el cuerpo o muslo trozándolo del primer golpe, sus proporcionadas para tragar cualquier mole.

Esta descripción de las mantas y su ferocidad carnívora también fue relatada por otros cronistas e incluso aparece dibujada en los Drake Manuscripts (llustración 1) (O’Brian, 1996). De esta manera, puede señalarse que los paisajes caribeños visitados por fray Înigo Abbad y Lasierra tendrán como elementos diferenciadores del universo cultural del autor, la presencia de animales marinos peligrosos, la importancia del conocimiento de las corrientes y de los fenómenos climáticos y, al mismo tiempo, las riquezas naturales que harán de estos territorios ultramarinos de la corona un lugar singular para la evangelización y para apuntalar el desarrollo económico imperial.

llustración 1. Representación de una manta con respecto al tamaño de un humano

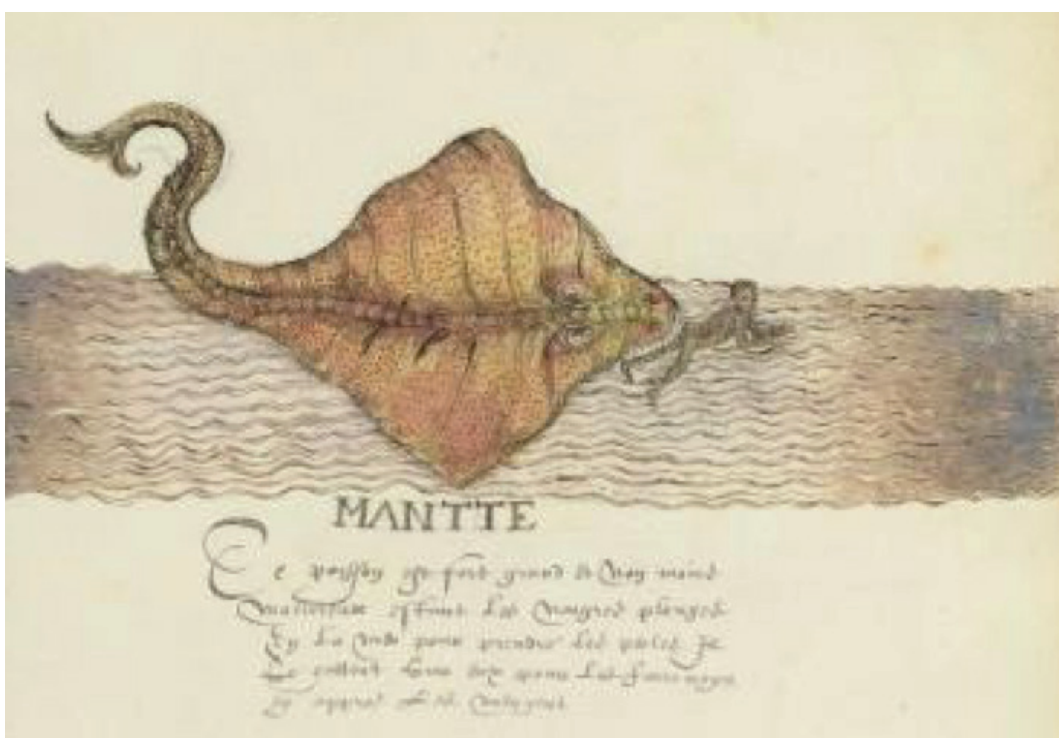

Fuente: Drake Manuscripts folios 46v -47r (O’Brian, 1996). 


\section{Las construcciones sociales de los habitantes de estos territorios}

Las construcciones sociales han sido ampliamente estudiadas desde el punto de vista teórico por Berger y Luckmann (1968), estos autores dejaron claro que toda narración o relato es, al mismo tiempo, una interpretación de la realidad. Estas miradas siempre tendrán un componente social que las realiza y que al mismo tiempo las determina. En palabras de Mignolo:

tanto el productor (o el autor) escribe su texto respondiendo a un horizonte de expectativas de su audiencia; como que la audiencia interpreta el texto en cuestión sobre el horizonte de expectativas que el texto orienta por la clase a la cual pertenece (1981, p. 360).

Esta perspectiva será sumamente importante a la hora de comprender y analizar las construcciones de los habitantes del Caribe hispano de la segunda mitad del siglo XVIII que realiza el viajero. Sobre esta construcción, fray Ínigo Abbad y Lasierra estructuró su texto en función de dos segmentos temporales, el pasado desde la Conquista y Colonización, y luego el presente etnográfico desde el cual él construye la realidad que observa.

\section{Sobre el pasado}

El relato sobre el pasado del Caribe hispano, como Abbad y Lasierra señaló, lo realiza sobre la base de su propio estudio de los cronistas, dentro de los que él cita se encuentran Antonio de Herrera y Tordesillas, quien en 1601 escribe Descripción de las Indias Occidentales, y GuillaumeThomas Raynals, quien publica en 1770 su Historia filosófica y política de los establecimientos y del comercio de los europeos en las dos Indias. La interpretación que nos ofrece nuestro viajero será característica de los hombres ilustrados de su época, pues Abbad y Lasierra condenará el trato dado a los indígenas por los primeros europeos que poblaron esas tierras cuando señala que "en 1511 repartió los Indios entre los españoles para el servicio personal de sus haciendas y de las minas, según se acostumbraba entonces en América, con el nombre de encomiendas". Así, continúa diciendo que "Los indios, que despechados de ver perdida su libertad, resolvieron acabar con todos los españoles que havia en la isla encargándose cada cacique de quitar la vida en el dia señalado alos que se hallasen en sus respectivas jurisdicciones". Pero no solo será una condena de tipo histórico puesto que, para nuestro viajero, esta seguirá siendo la causa principal del atraso y el poco provecho económico que la corona obtiene de estas regiones.

Asimismo, nuestro viajero también dará vida nuevamente a los indígenas caribes, a quienes numerosas líneas dedicaron los primeros cronistas de Indias y los cartógrafos europeos que tanto énfasis pusieron en sus mapas a la hora señalar su ubicación. Fray Íñigo Abbad y Lasierra relata que ante el cruel trato 
que recibían en la isla de Puerto Rico "Los indios llamaron en su socorro a los carives de las yslas de Barlovento, estos acudieron con tanta tenacidad que tuvieron a los españoles en un continuo conflicto hasta el año de mil quinientos treinta", estos indígenas según señala Abbad y Lasierra:

dieron muerte a ochenta hombres, que encontraron por toda la ysla, algunos" y la repuesta de los europeos fue que "tomaron la resolución mas barbara, de salir a campaña, con animo de estinguirlos, para cuio efecto, se proveyeron de armas y de perros y salieron a caza de indios.

La continua repetición de episodios parecidos a este también será condenada por Abbad y Lasierra al considerar que los mismos eran una muestra de que muchos hispanos eran parte del problema en las Indias.

Sobre el pasado de Margarita y Trinidad, será siempre determinado en señalar que estas islas estuvieron originalmente bajo la órbita e influencia de la isla de Cubagua y el centro perlífero que en ella se erigió en los primeros momentos de la Conquista y Colonización del Caribe. Allí se fundó la Nueva Cádiz, lugar de asiento de lo que fuera la pesquería de perlas más importante de principios del siglo XVI, sobre las causas de su destrucción señalará "por la falta de aguas que padecían en está viéndose precisados a conducirla del río Cumaná que dista siete leguas, y por la persecución de los caribes y los piratas franceses", el viajero posteriormente señala que esta misma ciudad sería refundada como el Puerto de la Mar y más adelante como ciudad de la Asunción, ambas ubicadas en la isla de Margarita.

\section{Su presente etnográfico}

El relato sobre el presente de la diversidad étnica, con el que él se encuentra en la isla de Puerto Rico, queda bien resumido cuando señala que "de tal suerte que siendo esta ysla muy poblada de indios, oy solo existen tres familias de estos en toda ella, aunque se encuentran en los bosques perros monteses que llaman cimarrones". Sobre la presencia de los negros dirá que "selos vende tan caros, y precisamente a dinero de contado, que son pocos los vecinos que pueden comprarlos y por consiguiente les faltan brazos para el cultivo y se dedican a la cria de ganando para lo que no necesitan esclavos" (Tabla 2).

Tabla 2. Relación de los habitantes de las provincias visitadas por fray Înigo Abba y Lasierra

\begin{tabular}{|l|l|l|l|}
\hline Lugar & Curas & Vecinos & Almas \\
\hline $\begin{array}{l}\text { Isla de Puerto } \\
\text { Rico }\end{array}$ & 16 & 4006 & Sin datos \\
\hline Isla de Margarita & 6 & 2105 & 14168 \\
\hline Isla de Trinidad & 4 & 408 & 2065 \\
\hline
\end{tabular}

Fuente: Elaboración propia. 
Pondrá mucha atención fray Îñigo a lo que él denominará la pobreza en la que viven los habitantes de estas islas, así como la incapacidad de los gobernantes para explotar estos territorios adecuadamente en beneficio de la corona. Dentro de los grandes errores de los gobernantes, señalará su trato para con los nativos y esclavos africanos "con esta inhumana crueldad, quedo la ysla desierta y sin brazos para el beneficio delas tierras y minas" él mismo preguntará a los grupos más desposeídos sobre su pobre suerte y estos "la atribuyen al despotismo, y la opresión delos gobernadores" mientras que cuando interrogó al respecto a estos últimos, señalaron que "la causa de estar la ysla tan pobre e inculta, responden que por desidia delos naturales”. Su conclusión al respecto, será la siguiente:

yo he visto por la experiencia, que unos, y otros tienen razón, y añado que la causa principal porque en esta ysla, ni el resto de la América, no se produce al rey ni a los particulares las inmensas riquezas que pudiera, son las compañías, y el mal método de hacer el comercio.

La conclusión anterior, da cuenta del interés del viajero a la hora de realizar su visita y posteriormente a la hora de comunicarla en su diario. Sobre el carácter de los habitantes con los que convivió en su visita, fray Íñigo Abbad y Lasierra marcará también una distinción importante. A los habitantes de Puerto Rico los describió de la siguiente manera: "el carácter de estos isleños, no es fácil definirlo es mezclado, y equivoco, por lo general son fantásticos y dominantes con los iguales, simulados y abatidos con los superiores, y en observación son perezosos y pobres", mientras que para referirse a los habitantes de la isla de Margarita señalará que:

estos isleños en general son muy afables y cariñosos en su trato, reciven a los huéspedes en sus casas con la maior humanidad, mateniendolos con franqueza hasta donde llegan sus haveres son muy propensos a navegar, buscando en la mar los medios de subsistir que les niega la tierra, y asi son contrabandistas de oficio, pescadores por necesidad, y corsarios por inclinación a todas las expediciones de mar en que son tan diestros e intrépidos (llustración 2).

Ilustración 2. Navegantes en el mar Caribe

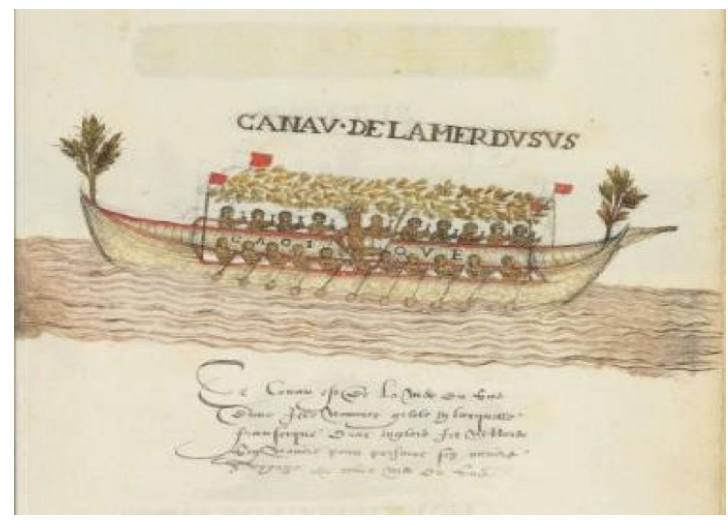

Fuente: Drake Manuscripts folios 43v-44i (O’Brian, 1996).

Cuadernos Inter.C.a.mbio sobre Centroamérica y el Caribe, Vol. 15, No. 2, octubre 2018-marzo 2019, 26-44 https://revistas.ucr.ac.cr/index.php/intercambio / DOl: https://doi.org/10.15517/c.a..v15i2.34800 
Esta distinción muy probablemente estuvo influencia por la protección que los monarcas españoles tuvieron desde muy temprano con los "naturales" de la isla de Margarita, para los cuales fue incluso por orden real prohibida cualquier tipo de encomienda. Esta construcción será completada cuando señala la prosperidad en la que se encuentra Margarita comparada con la de Puerto Rico y Trinidad, señalando que:

[en] ocaciones que en otras partes se carece de todo por la falta de comercio, en esta ysla se halla todo más abundante y varato pues en las incursiones que hacen en las yslas cogen de sus pueblos y haciendas los frutos, esclavos y hasta los niños que encuentran en ellas, estos suelen rescatarlos a buen precio.

Es de hacer notar que nuestro autor encuentra en su paso por las islas del caribe diferencias notables entre las poblaciones indígenas que habitaban estas islas, aunque no ofrece una reflexión etnológica de las diferencias señaladas. Asimismo, da cuenta de las redes de relaciones que existían entre los diferentes grupos indígenas en el Caribe, así como sus amplias habilidades para la navegación circuncaribeña, dejando de lado algunas representaciones de los indígenas de la época como grupos pequeños que viven aislados unos de otros. Es también importante señalar que, a pesar de las constantes referencias de nuestro viajero a las fuentes históricas, será sumamente relevante para él dar cuenta del presente etnográfico más allá de las representaciones históricas y míticas que de los habitantes de esta región se habían hecho hasta la fecha.

\section{Consideraciones finales}

La posibilidad de revisitar el Caribe de la segunda mitad del siglo XVIII a través del diario de "Viage a la America" de fray Íñigo Abbad y Lasierra, constituye una oportunidad para pasearse por un vasto y rico universo de datos sobre los paisajes culturales y sobre los habitantes que dieron vida a esos territorios, por lo que es necesario señalar que esta aproximación no agota todas las lecturas posibles de estos múltiples datos y que acercarse a ellos a partir de una ponderación política, temporal y cultural constituye una requisito ineludible para poder realizar una interpretación adecuada de los mismos. Tomando estas previsiones hemos podido acceder a una doble lectura del diario de viajes, la primera es una antropológica, centrada en comprender el imaginario europeo de la época que se encarnó en nuestro viajero. La segunda es sociohistórica, pues este relato constituye una etnografía de las islas caribeñas, de las condiciones de sus habitantes en términos políticos y económicos, de sus territorios y de sus paisajes culturales.

La lectura antropológica nos permitió apreciar el interés de nuestro viajero por producir un diario que fuera útil a sus lectores, es decir que sirviera como una especie de guía tanto a la monarquía como a los potenciales inversores en los territorios americanos y que sirviera al mismo tiempo para llevar 
adelante las reformas que él consideraba eran urgentes para poder maximizar el aprovechamiento económico que hasta la fecha se había hecho de las Américas. De ahí la importancia que este viajero otorga en su construcción del paisaje a las relaciones entre europeos, africanos e indígenas, los cuales con excepción de los "naturales" de la isla de Margarita, quienes eran considerados nobles por su pronta alianza con la corona hispana a principios del siglo $\mathrm{XVI}$, eran víctimas de un trato excesivamente cruel que, lejos de potenciar el aprovechamiento de los territorios, era el principal obstáculo para el desarrollo definitivo de las islas del Caribe, pues estas acciones profundizaban el conflicto social tanto con los indígenas como con los africanos. Asimismo, es necesario resaltar que, a pesar de la clara visión utilitaria que quería infundir nuestro viajero a su diario, este tampoco escapó a la influencia de las geografías míticas que aun formaban parte del imaginario europeo de la época y que se había instalado especialmente sobre las ideas que existían de la presencia de los caribes antropófagos, indígenas americanos habitantes de las islas de este mar del Atlántico a los cuales múltiples veces hizo referencia nuestro viajero.

La lectura sociohistórica nos permitió acceder a la composición étnica y a la infraestructura eclesiástica de los paisajes de la región caribeña; de esta manera, podemos concluir el peso relativo de cada una de estas islas para el total de la diócesis cuyo centro tenía la isla de Puerto Rico. En esta se alojaban 16 curas mientras que en Margarita solo 6 y en Trinidad solo 4, los cuales eran además proporcionales a la población que tenían las islas para la fecha, siendo la más poblada Puerto Rico, seguida por Margarita y Trinidad. Esto también refleja los cambios en el paisaje ocurridos en los dos siglos anteriores de ocupación hispana puesto que la otrora costa de las perlas durante el temprano siglo XVI llegó a ser una de las regiones más importantes para la corona por su riqueza perlífera, y para la fecha había sido desplazada considerablemente tanto en el número de habitantes como de construcciones eclesiásticas y pueblos, puesto que en Puerto Rico visitó en más de 30 pueblos, contra los apenas seis que visitó en Margarita y nueve en la isla de Trinidad.

\section{Referencias}

Abbad y Lasierra, Fray Íñigo. ([1772-1774]. 1974). Viage a la América. Caracas: Ernesto Armitano (Ed.).

Acosta, Vladimir. (1992). El continente prodigioso: mitos e imaginario medieval en la conquista americana. Caracas: Universidad Central de VenezuelaEdiciones de La Biblioteca.

Acosta, Vladimir. (1993). Viajeros y maravillas. Caracas: Monte Ávila Editores- 
Amodio, Emanuele. (1993). Formas de la Alteridad: Construcción y difusión de la imagen del indio americano en Europa durante el primer siglo de la conquista de América. Quito: Ediciones Abya-yala.

Amodio, Emanuele. (2002). La antropología Salvaje. Conocimiento del otro y política imperial durante el Antiguo Régimen. Debate y perspectivas, 2, 191-218.

Andreu, Antonio. (1993). Andadura americana de fray Înigo Agustín Abbad y Lasierra y algunos pasos más. Argensola, 107, 189-234.

Arvelo-Jiménez, Nelly y Biord-Castillo, Horacio. (1989). Reflexiones antropológicas sobre el "Ensayo de Historia Americana" de Felipe Salvador Gilij. Revista Montalbán, 21, 69-90.

Berger, Peter y Luckmann, Thomas. (1968). La construcción social de la realidad. Buenos Aires: Amorrortu.

Bracho, Jorge. (2009). La historia Universal y el despliegue occidental: cultura, narrativa y enseñanza. Caracas: UPEL-IPC.

Brückner, Martin (Ed.). (2011). Early American Cartographies. Chapel Hill: The University of North Carolina Press.

Calzadilla, Pedro. (2005). Por los caminos de América en el siglo de las luces. Caracas: Fondo Editorial Trópykos.

Gilij, Felipe. ([1782] 1955). Ensayo de historia americana: o sea, Historia natural, civil y sacra de los reinos, y de las provincias de Tierra Firme en la América meridional (Vol. 88). Bogotá: Editorial Sucre.

Gumilla, José. (1745). El Orinoco ilustrado y defendido, historia natural, civil, y geographica de este gran rio (Vol. 1). Madrid: Manuel Fernández, impresor.

Cunill Grau, Pedro. (abril-junio 2004). "Biodiversidad y recursos naturales venezolanos para la sensibilidad euroamericana. Sus paisajes geohistóricos (siglos XV-XIX)" Boletín de la Academia Nacional de la Historia (Venezuela), 87(346), 25-156.

Harris, Marvin. (1998). Antropología cultural. Madrid: Alianza Editorial.

Lemmo, Angelina. (1983). Historiografía Colonial de Venezuela. Caracas: Fondo Editorial de Humanidades y Educación-Universidad Central de Venezuela.

Martínez, Eduardo. (2017). El puesto de la cultura en el paisaje. Treballs de la Societat Catalana de Geografía, 84, 37-49. 
Martínez-Sarrado, Sergio. (2001). Evangelización y cultura: un enriquecimiento mutuo. Según Agustín Íñigo Abbad y Lasierra. En Enrique de la Lama Cereceda. Dos mil años de evangelización: los grandes ciclos evangelizadores. (pp. 525-542). Pamplona: Universidad de Navarra, Servicio de Publicaciones.

Mignolo, Walter. (1981). El metatexto historiográfico y la historiografía indiana. MLN, 96(2), 358-402.

Montenegro, Giovanna. (2017). Conquistadors and Indians "Fail" at Gift Exchange: An Analysis of Nikolaus Federmann's Indianische Historia. MLN, 132(2), 272-290.

Morelli, Federica. (2008). La redefinición de las relaciones imperiales: en torno a la relación reformas dieciochescas/independencia en América. Nuevo Mundo Mundos Nuevos. Nouveaux mondes mondesnouveauxNovo Mundo Mundos Novos-New world New worlds. DOl: 10.4000/ nuevomundo.32942

Navarrete Sánchez, Rodrigo. (2004). El pasado con intención: hacia una reconstrucción crítica del pensamiento arqueológico en Venezuela (desde la colonia al siglo XIX). Caracas: Ediciones FaCES UCV-Fondo editorial Tropykos.

O'brian, Patrick. (1996). Histoire naturelle des Indes: The Drake Manuscript in the Pierpont Morgan Library. New York: Norton.

Perera, Miguel Ángel. (1993). La mirada perdida: Etnohistoria y Antropología Americana del Siglo XVI. Caracas: Monte Ávila Editores, Latinoamericana.

Pino Iturrieta, Elías y Calzadilla, Pedro. (1993). La Mirada del otro: viajeros extranjeros en la Venezuela del siglo XIX. Caracas: Fundación Bigott.

Rodríguez Velásquez, Fidel. (2017). Representación e historiografía: miradas múltiples sobre el pasado de la isla de Cubagua (1894 -2016). Historia da historiografía: International Journal of Theory and History of Historiography, (23), 28-43.

Von Grafenstein, Joanna. (2000). El Caribe en la política imperial de España, siglo XVIII. Tzintzu. 32.

\section{Agradecimientos}

Quiero expresar mi agradecimiento al Dr. Jorge Bracho de la cátedra de Historia del Caribe de la Maestría en Historia de las Américas de la Universidad Católica Andrés Bello (UCAB) y a la antropóloga Julimar Mora Silva de la Escuela de Sociología de la Universidad Central de Venezuela por sus comentarios críticos al manuscrito; al Dr. Horacio Biord Castillo 
Jefe del Laboratorio de Etnohistoria y Oralidad del Centro de Antropología del Instituto Venezolano de Investigaciones Científicas (IVIC), porque las discusiones constantes que tenemos sobre los temas de identidad, alteridad e historiografía me han ayudado considerablemente a construir una visión más acabada sobre estos temas; al arquitecto Segundo Jiménez García de la Unidad de Dibujo y Diseño, quien tuvo la gentileza y amabilidad de diseñar el mapa 1. Finalmente, quisiera agradecer a los revisores anónimos, sus comentarios y observaciones permitieron enriquecer el manuscrito. 